\title{
Lateral and medial epicondylitis
}

\section{Lateral epicondylitis}

\section{Introduction}

History: The diagnosis of lateral humeral condyle pain was first made by Runge ${ }^{1}$ in 1873 when describing pain and difficulty with writing. ${ }^{1}$ Major ${ }^{2}$ in 1883 used the term "lawn tennis elbow" in association with the same diagnosis being common in tennis players. Since that time, much research and trial have been dedicated to studying and treating this prevalent elbow pathology. Nirschl ${ }^{3,4}$ has since described the histopathology of this condition as a degenerative tendinopathy and a greater understanding of the cause of this diagnosis has led to multiple treatment proposals over the last twenty to thirty years. Cyriax ${ }^{5}$ in 1936 stated that "operation does not appear to give results superior to [the writer's] non operative treatment methods" and this debate has continued to persist as more recent non operative and operative treatment options have emerged. Despite the lack of consensus with regards to an optimal treatment algorithm, our understanding of lateral elbow tendinosis has continued to advance with the goal of improving patient outcomes in the future.

\section{Epidemiology, etiology and pathology}

Epidemiology: The prevalence of lateral epicondylitis has been estimated to range from one to three percent of the population. ${ }^{6}$ Men and women are equally affected and the typical age range of patients with lateral epicondylitis is 35-54 years. . $2,5,7-14^{\text {Although }}$ given the name "tennis elbow", only about 10 percent of those with lateral epicondylitis describe this as an associated activity. ${ }^{8}$ Numerous studies have been performed examining occupational factors related to elbow tendinopathies, including lateral epicondylitis.

Work-related movements and risk factors attributing to the cause of this tendinopathy include repetitive and forceful elbow flexion and extension, ${ }^{12}$ repetitive wrist extension and pronation/supination. ${ }^{8,13,15}$ non-neutral position of hands and arms during work and the use of heavy hand tools. ${ }^{11}$ Shiri et al. ${ }^{9}$ performed a study of the Finnish general population in 2006 and identified a combination of repetitive and forceful activities as well as longer exposure to these activities as risk factors for lateral epicondylitis. ${ }^{9}$

In addition to work-related factors, other risk factors for lateral epicondylitis that have been identified in epidemiological studies include history of rotator cuff pathology, De Quervains disease, carpal tunnel syndrome and corticosteroid use. There has been a strong correlation of smoking history as a risk factor for developing elbow tendinoses and more debate exists regarding the role of obesity and diabetes mellitus in the population with lateral epicondylitis. ${ }^{7,9,14}$ In addition, no consensus has been established between the relationship of socioeconomic class and diagnosis and prognosis. Haahr \& Anderson ${ }^{10}$ performed a one-year follow-up of a general population of 266 cases diagnosed with lateral epicondylitis to analyze prognostic factors. They found no relation between the treatment given/ chosen and prognosis, whereas poor prognostic factors included high perceived baseline pain and manual labor. ${ }^{10,11}$ In this study, 83 percent of patients improved after one year, which is comparable to other literature analyzing various non-operative treatment options. However, recurrence rates of up to 50 percent have been reported after six months, ${ }^{16}$ leading to other treatment options such as operative intervention.
Volume 3 Issue 2 - 2015

\author{
Mark Yuhas, Srinath Kamineni \\ Department of Orthopaedics and Sports Medicine, University \\ of Kentucky, USA
}

Correspondence: Srinath Kamineni, Department of Orthopaedics and Sports Medicine, University of Kentucky, Lexington, USA, Email srinathkamineni@gmail.com

Received: June 26, 2015 | Published: August 31, 2015

Etiology and pathology: Early studies of the etiology of lateral epicondylitis by Goldie et al. ${ }^{15}(12)$ as well as Coonrad \& Hooper ${ }^{17}$ identified a degenerative process of the extensor origin as the cause of this pathology. Cyriax ${ }^{5}$ described the extensor brevis as a potential anatomical site of lateral epicondylitis in 1936 and multiple authors ${ }^{3,4,17,18}$ since this time have cited the ECRB (extensor carpi radialis brevis) as the primary macroscopic origin of lateral epicondylitis. Nirschl has also described based on operative intervention that degenerative changes in the EDC (extensor digitorum communis) is present in approximately $50 \%$ of cases and occasionally pathological changes are seen on the undersurface of the ECRL (extensor carpi radialis longus). Multiple theories have been proposed with regards to the pathogenesis of lateral epicondylitis, with the most frequent research indicating repetitive contractures of the extensor mechanism leading to microscopic tears and eventually degenerative tendinosis. ${ }^{3,4,17,19,20}$ A recent anatomical study indicated the unique relationship of the ECRB fibers and lateral condyle can lead to abrasion and wear with elbow motion. ${ }^{21}$

The pathology of lateral epicondylitis was initially thought to be due to an inflammatory process. Nirschl and colleagues have demonstrated that the pathological process is in fact not inflammatory but rather a degenerative tendinosis., ${ }^{3,422-24}$ The described histology of this "angiofibroblastic hyperplasia", as termed by Nirschl ${ }^{3}$ consist of disorderly tendon fibers in combination with fibroblasts and atypical vascular granulation-like tissue, focal hyaline degeneration and calcific debris ${ }^{22}$ surrounded by hypercellular and degenerative tissues, although additional molecular studies have shown that fibro cartilage may be a "normal" histological feature of aging tendons. ${ }^{25}$

The tendinosis in lateral epicondylitis is theorized to be caused by a failed response of tissue to repetitive micro tears primarily of the ECRB origin as well as hypovascular tissue of the tendon origin., 3 Studies focusing on the vascular supply to the lateral condyle and surrounding tendons include Bales et al. ${ }^{26}$ investigation in which India ink was injected into the vasculature of six frozen cadaveric arms. Two hypovascular zones were identified, one at the lateral epicondyle and one within the common extensor tendon. A second study by 
Oskarsson and colleagues found diminished intramuscular blood flow in the ECRB of elbows diagnosed with lateral epicondylitis compared with normal asymptomatic elbows using a laser-Doppler flowmetry system.

Although the presence of active inflammatory cells has not been demonstrated histologically, the role of a neurogenic inflammatory response to chronic pain in patients with lateral epicondylitis has been investigated. The up-regulation of NK-1 receptors in patients with chronic pain has been seen on PET scan when identifying radioligand NK-1 receptors. Substance P, a primary agonist for these pain receptors, has also been found in increased amount in tissues samples of patients with lateral epicondylitis..$^{27,28}$ These initial findings help to illustrate the complexity of treatment of chronic pain conditions such as recalcitrant lateral epicondylitis and the role of these studies is still evolving when incorporated with earlier pathological findings of this process.

\section{Presentation}

Typically, patients with lateral epicondylitis will present with pain over the lateral elbow, typically sharp with rare accompanied swelling. Occasionally, more diffuse lateral elbow tenderness is present along with radiating pain down the forearm. The onset is often insidious, with pain exacerbated with repetitive activities or a recent change in activities requiring wrist extension Patients may also complain of a difficulty holding objects and diminished grip strength may be present. Nirschl ${ }^{3}$ has described a modified pain phasing system describing the intensity and duration of a patient's pain. This system is based on the description by Blazina et al. ${ }^{29}$ for patellar tendon overuse and can be used for prognosis after specific interventions.

In addition to a focused elbow exam, it should be noted the importance of a thorough exam of the cervical spine and entire upper extremity is essential for conclusive diagnosis. On physical exam, point tenderness can be elicited at the origin of the EDC and ECRB, of which the footprint is located at the distal extent of the supracondylar ridge and slightly anterior of the midline longitudinal humeral axis. ${ }^{30}$ Less commonly, pain can be elicited with tenderness to palpation directly over the center of the lateral epicondyle. Pain with wrist extension, forearm pronation with the elbow extended is the most common upper extremity position that generates pain. Gardner ${ }^{31}$ in 1970 described the importance of the "chair test" in improving the clinical exam sensitivity. Patients experiencing pain near the lateral epicondyle when lifting a chair with one hand while the elbow is extended and forearm pronated are considered to have a positive test. Pain with maximal wrist flexion, active or passive, as well as resisted wrist or long finger extension may also indicate lateral epicondylitis as a source of lateral elbow pain, These exam maneuvers alone are not specific for the diagnosis of lateral epicondylitis and other sources of pain, such as radial tunnel syndrome , must be considered. ${ }^{32,33}$

\section{Differential diagnosis}

The differential diagnosis of lateral elbow pain includes multiple diagnoses near the elbow as well as throughout the upper extremity as well as the cervical spine. These diagnoses may occur as a separate pathology or concomitantly with lateral epicondylitis, further emphasizing the importance of a thorough history, physical exam and additional diagnostic workup. Radial tunnel syndrome should be included in the differential diagnosis, as the symptoms and exam can overlap with lateral epicondylitis symptoms. Radial tunnel syndrome and lateral epicondylitis have also been reported to occur simultaneously with an incidence of approximately five percent. ${ }^{33,34}$ Refractory cases most radial nerve entrapment at radial tunnel, which causes pain with resisted supination; Pain with resisted extension of the middle finger indicates radial nerve entrapment at ECRBMaudsleys test. ${ }^{34}$
a. Synovitis
b. Plica $^{35}$
c. Chondromalacia
d. Loose bodies or osteochondral lesion
e. Cervical radiculopathy or referred pain from another site in upper extremity

f. Ligamentous instability

\section{Diagnostic studies}

Imaging may provide limited decision making and diagnosis, but lateral epicondylitis mainly clinical diagnosis. Imaging studies may be most helpful in ruling out other sources of pathology which may be causing symptoms of lateral elbow pain.

a. Radiographs provide limited information, may demonstrate calcification near extensor origin or demonstrate loose bodies within the elbow joint. ${ }^{36}$

b. Ultrasound limited with high false sensitivity but low specificity. ${ }^{37-39}$

c. MRI demonstrates tendon thickening with increased $\mathrm{T} 1$ and T2 signal. Increased marrow T2 signal within epicondyle occasionally seen. ${ }^{39,40}$

d. Possible partial or full thickness tears at extensor origin. ${ }^{41}$

\section{Treatment}

Nonoperative Most cases of lateral epicondylitis can be treated nonoperatively. Cost-effectiveness analysis does not justify any specific treatment approach other than observation. ${ }^{42}$

i. Activity modification and NSAIDS.

ii. Bracing. ${ }^{43}$

iii. Physical therapy. ${ }^{44-47}$

iv. Injection. $^{48}$

v. Steroid. ${ }^{47,49-52}$

vi. Lidocaine and steroid: This is the commonest form of nonoperative treatment advocated by the authors. A single injection point is far less effective than multiple sites of injection (Figure 1A-C). Although complications are uncommon, always warn patients about depigmentation and fat atrophic changes at the injection site (Figure 2).
a. Botulinum toxin. ${ }^{53}$
b. Autologous blood. $50,51,54,55$
c. Platelet-rich plasma. ${ }^{52,55-58}$ 
i. Extracorporeal shock wave therapy. ${ }^{59-61}$

ii. Alternative medicines such as acupuncture, topical treatments, ${ }^{62}$ laser therapy, TENS. ${ }^{63}$
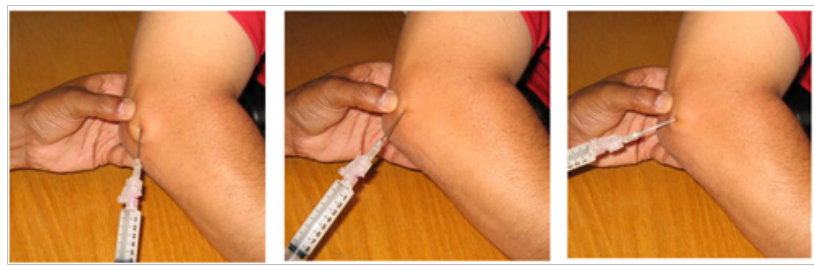

Figure IA-C Multi-perforate injection technique for injection of corticosteroid and local anesthetic into the anterior inferior aspect of the lateral epicondyle.

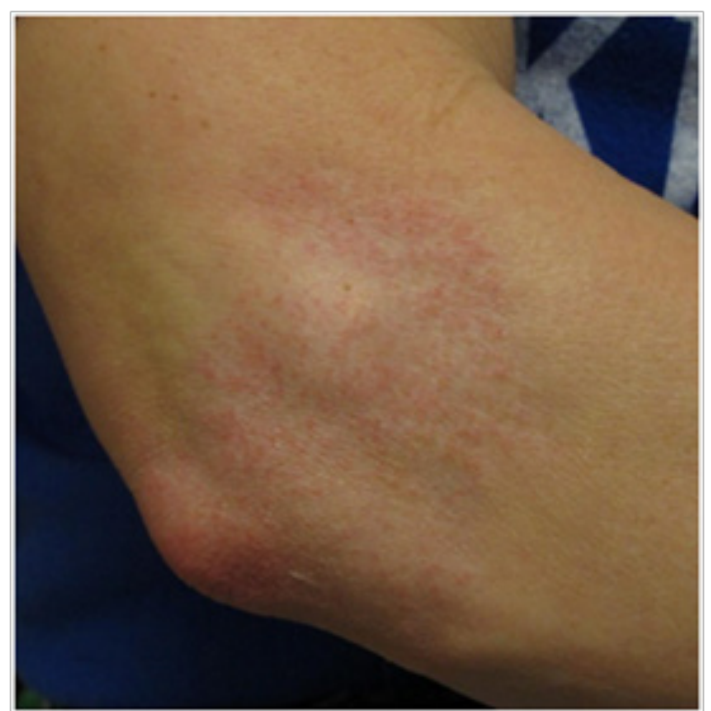

Figure 2 Adverse reaction to steroid injection for tennis elbow, Mild depigmentation and fat atrophy.

Operative: Indications include failed non-operative intervention

a. Surgical anatomy. ${ }^{64}$

b. Debridement.

c. Release tendon origin.

I. Arthroscopic or open ${ }^{65-68}$ Mini open including Nirschl technique $^{69,70}$ Long term results of arthroscopic release. ${ }^{71}$ The arthroscopic release is the commonest form of operative management in our practice (Figures 3-6).

II. Percutaneous release. ${ }^{72}$

III. Minimally invasive percutaneous microresection with TX 1 device $^{68}$ Microtenotomy. $^{73}$

IV. With or without repair.

V. Intraarticular or extraartricular. ${ }^{74}$

VI. Posterior synovial plica excision. ${ }^{75}$

a. Release of posterior interosseous nerve.

b. Anconeus rotation.

c. Denervation of lateral condyle.

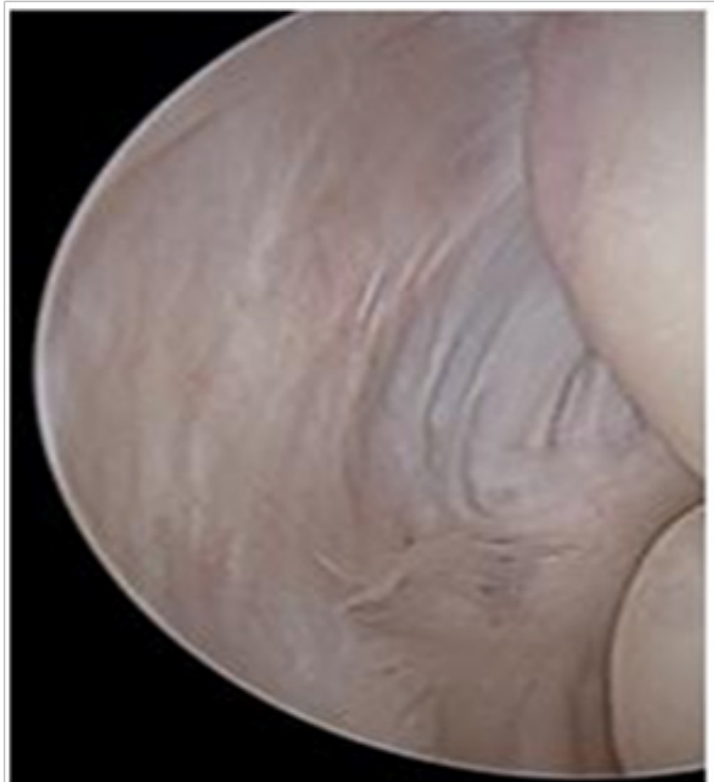

Figure 3 Lateral epicondylitis as viewed through the anteromedial portal.

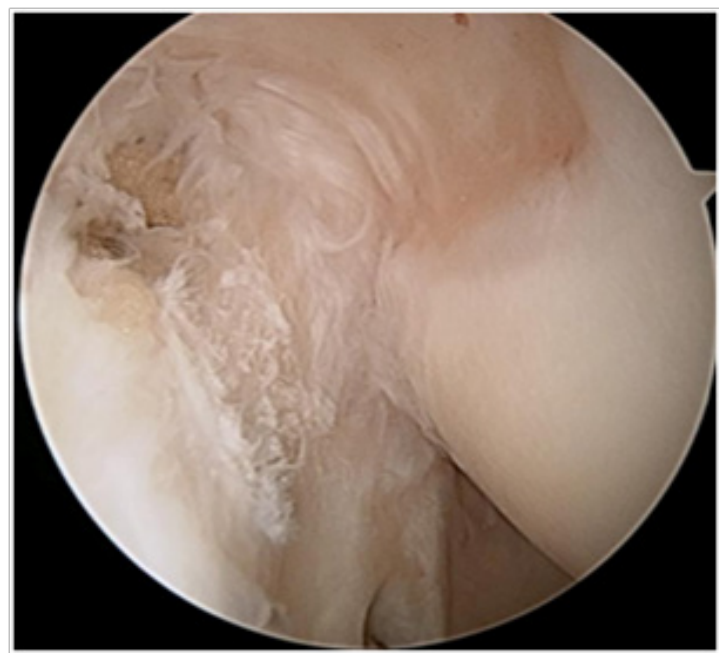

Figure 4 Minor fraying with a focal rupture of the ECRB.

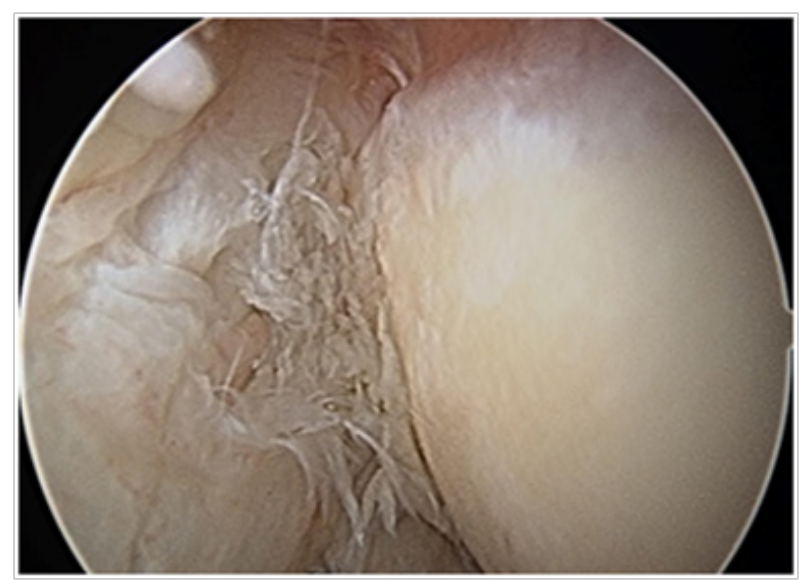

Figure 5 Arthroscopic view of frayed lateral capsule in Lateral epicondylitis. 


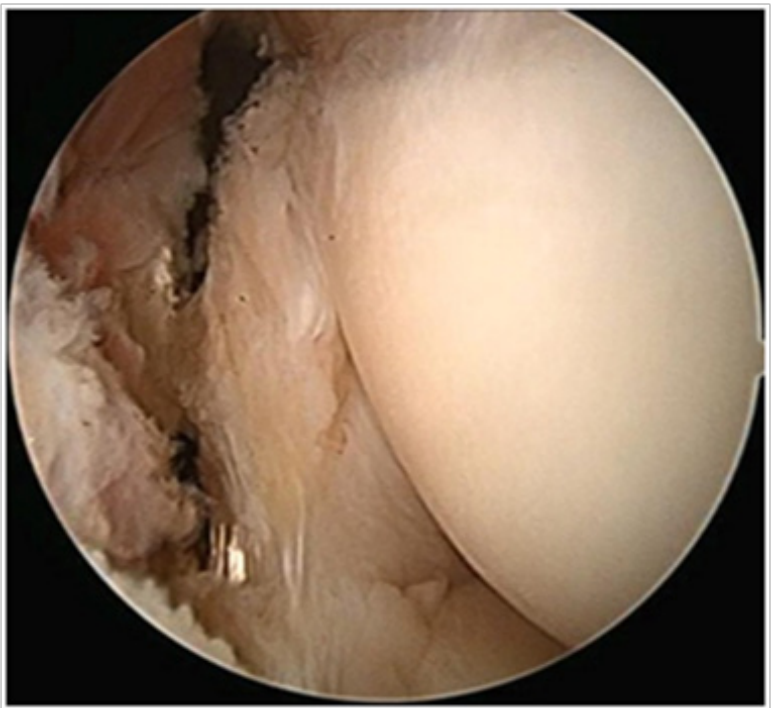

Figure 6 Arthroscopic tennis elbow release, with visualization and preservation of the $\mathrm{LCL}$

\section{Medial epicondylitis}

\section{Introduction}

a. Often referred to as "golfer's elbow".

b. Associated with sport, including racquet sports as well as overhead throwing athletes and golfing requiring repeated valgus load to the elbow.

c. Due to repetitive activities, much less commonly reported than lateral epicondylitis.

\section{History}

a. Morris original description of medial elbow pain in rowers.

b. Commonly described in association with throwing athletes as well as labor which requires repetitive pronation and wrist flexion.

\section{Etiology and pathology}

a. Overall prevalence of between 0.4 and 1.3 percent.

b. Represents of 9.8 to 20 percent of all cases of epicondyltis.

c. Average age is between 40 and 50 years, also a subset of patients with medial epicondylitis who are younger, overhead throwing athletes.

d. Risk factors include repetitive activities, obesity, and smoking.

e. Degenerative condition representing tendinosis similar to lateral epicondylitis.

f. Pronator teres and Flexor Carpi Radialis commonly involved, less common involvement of other tendons of flexor-pronator mass.

g. Histology is very similar to lateral epicondylitis, representing a "tendinosis" with angiofibroblastic hyperplastic changes present. ${ }^{76-88}$

\section{Presentation}

a. Pain / swelling over medial epicondyle (Figure 7).

b. Discomfort with resisted wrist flexion.

c. Positive Tinel's sign at elbow.

d. Pain with valgus stress of elbow indicates (UCL disruption or injury).

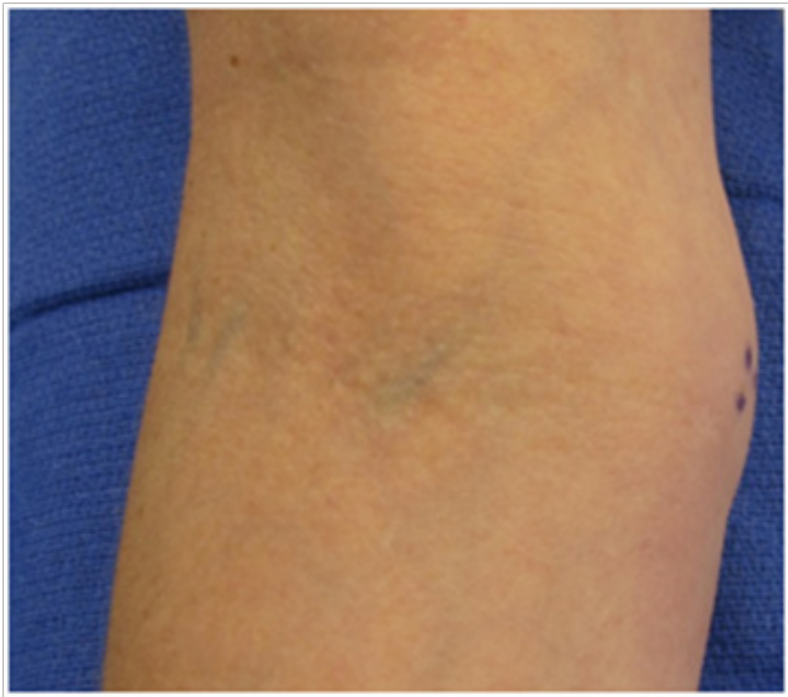

Figure 7 Swollen medial epicondylitis, marked for the most painful area.

\section{Differential diagnosis}

1. Loose bodies or osteochondral lesion

2. Ulnar neuritis seen to be associated in up to 60 percent of cases.

3. Ulnar collateral ligament disruption.

4. Radiculopathy (C6 and C7)

\section{Diagnostic studies}

a. Radiographs may show degenerative changes, also may demonstrate medial epicondyle calcifications.

b. Ultrasound a useful adjunct study, hypoechogenic area.

c. EMG studies often demonstrate normal findings.

d. MRI useful for similarly presenting conditions, including UCL disruption.

Treatment: Similar to lateral epicondylitis

\section{Non-operative}

a. Activity modification, ice, NSAIDS

b. Physical therapy, bracing

c. Injections

d. Platelet-rich plasma

e. Steroids

f. Steroids and lidocaine

g. Autologous blood 


\section{Operative}

i. Indications are not common, reserved for patients who have failed conservative therapy for atleast six months.

ii. Surgical anatomy, interval between pronator teres and FCR, need to be aware of ulnar nerve (complication).

iii. Debridement and repair of flexor pronator mass (Figure 8).

iv. Repair of flexor pronator group.

v. Arthroscopic versus open technique.

vi. Ulnar nerve release with possible transposition.

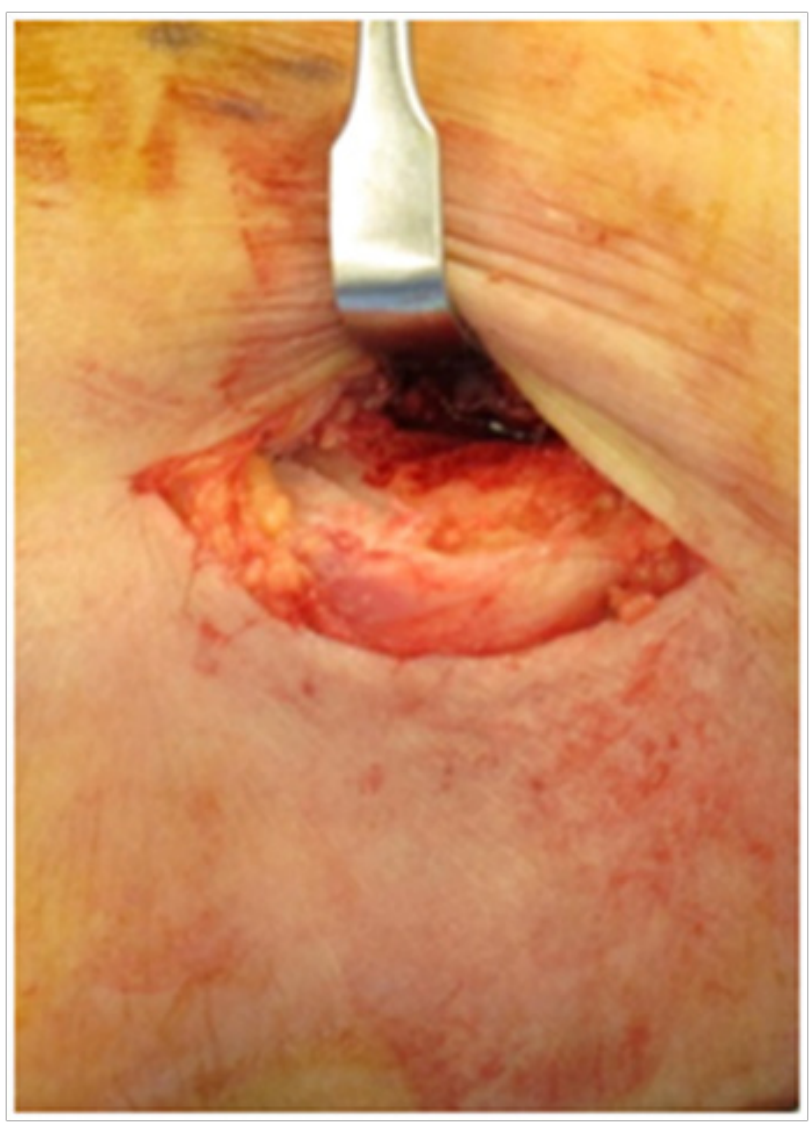

Figure 8 Medial epicondylitis release through medial approach.

\section{Acknowledgments}

None.

\section{Conflicts of interest}

The authors declare there is no conflict of interest.

\section{References}

1. Runge F. Zur genese und behandlungdes schreibekramfes. Berl Klin Wochenschr. 1873;10:245.

2. Major HP. Lawn-tennis elbow. BMJ. 1883;2:557.

3. Nirschl RP, Ashman ES. Elbow tendinopathy: tennis elbow. Clin Sports Med. 2003;22(4):813-836.

4. Nirschl RP, Pettrone FA. Tennis elbow: The surgical treatment of lateral epicondylitis. J Bone Joint Surg Am. 1979;61(6A):832-839.
5. Cyriax JH. The pathology and treatment of tennis elbow. J Bone Joint Surg. 1936;18(4):921-940.

6. Verhaar JA. Tennis elbow: Anatomical, epidemiological and therapeutic aspects. Int Orthop. 1994;18(5):263-267.

7. van Rijn RM, Huisstede BM, Koes BW, et al. Associations between work-related factors and specific disorders at the elbow: a systematic literature review. Rheumatology (Oxford). 2009;48(5):528-536.

8. De Smedt T, de Jong A, Van Leemput W, et al. Lateral epicondylitis in tennis: update on aetiology, biomechanics and treatment. Br J Sports Med. 2007;41(11):816-819.

9. Shiri R, Viikari-Juntura E, Varonen H, et al. Prevalence and determinants of lateral and medial epicondylitis: a population study. Am J Epidemiol. 2006;164(11):1065-1074.

10. Haahr JP, Andersen JH. Physical and psychosocial risk factors for lateral epicondylitis: a population based case-referent study. Occup Environ Med. 2003;60(5):322-329.

11. Haahr JP, Andersen JH. Prognostic factors in lateral epicondylitis: a randomized trial with one-year follow-up in 266 new cases treated with minimal occupational intervention or the usual approach in general practice. Rheumatology (Oxford). 2003;42(10):1216-1225.

12. Walker-Bone K, Palmer KT, Reading I, et al. Occupation and epicondylitis: a population-based study. Rheumatology (Oxford). 2012;51(2):305-310.

13. Herquelot E, Guéguen A, Roquelaure Y, et al. Work-related risk factors for incidence of lateral epicondylitis in a large working population. Scand J Work Environ Health. 2013;39(6):578-588.

14. Titchener AG, Fakis A, Tambe AA, et al. Risk factors in lateral epicondylitis (tennis elbow): a case-control study. J Hand Surg Eur. 2013;38(2):159-164.

15. Goldie I. Epicondylitis lateralis humeri (epicondylalgia or tennis elbow). A pathogenetical study. Acta Chir Scand Suppl. 1964;57(Suppl 339):1.

16. Binder AI, Hazleman BL. Lateral humeral epicondylitis-a study of natural history and the effect of conservative therapy. Br J Rheumatol. $1983 ; 22(2): 73-76$

17. Jafarian FS, Demneh ES, Tyson SF. The immediate effect of orthotic management on grip strength of patients with lateral epicondylosis. $J$ Orthop Sports Phys Ther. 2009;39(6):484-489.

18. Hamilton PG. The prevalence of humeral epicondylitis: a survey in general practice. JR Coll Gen Pract. 1986;36(291):464- 465.

19. Greenbaum B, Itamura J, Vangsness CT, et al. Extensor carpi radialis brevis. An anatomical analysis of its origin. J Bone Joint Surg Br. 1999;81(5):926-929.

20. Kraushaar BS, Nirschl RP. Tendinosis of the elbow (tennis elbow): Clinical features and findings of histological, immunohistochemical, and electronmicroscopy studies. J Bone Joint Surg Am . 1999;81(2):259-278.

21. Almekinders LC. Tendinitis and other chronic tendinopathies. J Am Acad Orthop Surg. 1998;6(3):157-164.

22. Bunata RE, Brown DS, Capelo R. Anatomic factors related to the cause of tennis elbow. J Bone Joint Surg Am. 2007;89(9):1955-1963.

23. Regan W, Wold LE, Coonrad R, et al. Microscopic histopathology of chronic refractory lateral epicondylitis. Am J Sports Med. 1992;20(6):746-749.

24. Galliani I, Burattini S, Mariani AR, et al. Morpho-functional changes in human tendon tissue. Eur J Histochem. 2002;46(1):3-12.

25. Faro F, Wolf JM. Lateral epicondylitis: review and current concepts. $J$ Hand Surg Am. 2007;32(8):1271-1279. 
26. Milz S, Tischer T, Buettner A, et al. Molecular composition and pathology of entheses on the medial and lateral epicondyles of the humerus: a structural basis for epicondylitis. Ann Rheum Dis. 2004;63(9):10151021

27. Bales CP, Placzek JD, Malone KJ, et al. Microvascular supply of the lateral epicondyle and common extensor origin. J Shoulder Elbow Surg. 2007;16(4):497-501.

28. Ljung BO, Alfredson H, Forsgren S. Neurokinin 1-receptors and sensory neuropeptides in tendon insertions at the medial and lateral epicondyles of the humerus. Studies on tennis elbow and medial epicondylalgia. $J$ Orthop Res. 2004;22(2):321-327.

29. Peterson M, Svärdsudd K, Appel L, et. al. PET-scan shows peripherally increased neurokinin 1 receptor availability in chronic tennis elbow: visualizing neurogenic inflammation? PLoS One. 2013;8(10):e75859.

30. Blazina HE, Kerlan RK, Jobe FW. Jumper's knee. Orthop Clin North Am. 1973;4(3):665-678.

31. Cohen MS, Romeo AA, Hennigan SP, et al. Lateral epicondylitis: anatomic relationships of the extensor tendon origins and implications for arthroscopic treatment. J Shoulder Elbow Surg. 2008;17(6):954-960.

32. Gardner RC. Tennis elbow: diagnosis, pathology and treatment. Nine severe cases treated by a new reconstructive operation. Clin Orthop Relat Res. 1970;72:248-253.

33. Whaley AL, Baker CL. Lateral epicondylitis. Clin Sports Med 2004;23(4):677-691.

34. Stanley J. Radial tunnel syndrome: a surgeon's perspective. J Hand Ther. 2006;19(2):180-184.

35. Werner CO. Lateral elbow pain and posterior nerve entrapment. Acta Orthop Scand. 1979;Suppl 174:1-62.

36. Ruch DS, Papadonikolakis A, Campolattaro RM. The posterolatera plica: A cause of refractory lateral elbow pain. J Shoulder Elbow Surg. 2006;15(3):367-370.

37. Pomerance J. Radiographic analysis of lateral epicondylitis. J Shoulder Elbow Surg. 2002;11(2):156-157.

38. Kotnis NA, Chiavaras MM, Harish S. Lateral epicondylitis and beyond: imaging of lateral elbow pain with clinical-radiologic correlation. Skeletal Radiol. 2012;41(4):369-386.

39. Connell D, Burke F, Coombes P, et al. Sonographic examination of lateral epicondylitis. AJR Am J Roentgenol. 2001;176(3):777-782.

40. Martin CE, Schweitzer ME. MR imaging of epicondylitis. Skeletal Radiol. 1998;27(3):133-138.

41. Patten RM. Overuse syndromes and injuries involving the elbow: MR imaging findings. AJR Am J Roentgenol. 1995;164(5):1205-1211.

42. Hayter CL, Adler RS. Injuries of the elbow and the current treatment of tendon disease. AJR Am J Roentgenol. 2012;199(3):546-557.

43. Korthals-de Bos IB, Smidt N, van Tulder MW, et al. Cost effectiveness of interventions for lateral epicondylitis: results from a randomised controlled trial in primary care. Pharmacoeconomics. 2004;22(3):185195.

44. Meknas K, Odden-Miland A, Mercer JB, e al. Radiofrequency microtenotomy: a promising method for treatment of recalcitrant latera epicondylitis. Am J Sports Med. 2008;36(10):1960-1965.

45. Stasinopoulos D, Johnson MI. Cyriax physiotherapy for tennis elbow/ lateral epicondylitis. Br J Sports Med. 2004;38(6):675-677.

46. Cullinane FL, Boocock MG, Trevelyan FC. Is eccentric exercise an effective treatment for lateral epicondylitis? A systematic review. Clin Rehabil. 2014;28(1):3-19.
47. Smidt N, Assendelft WJ, Arola H, et al. Effectiveness of physiotherapy for lateral epicondylitis: a systematic review. Ann Med. 2003;35(1):5162.

48. SmidtN, van derWindtDA, Assendelft WJ, etal. Corticosteroid injections, physiotherapy, or a wait-and-see policy for lateral epicondylitis: a randomised controlled trial. Lancet. 2002;359(9307):657-662.

49. Krogh TP, Bartels EM, Ellingsen T, et al. Comparative effectiveness of injection therapies in lateral epicondylitis: a systematic review and network meta-analysis of randomized controlled trials. Am J Sports Med. 2013;41(6):1435-1446.

50. Smidt N, Assendelft WJ, van der Windt DA, et al. Corticosteroid injections for lateral epicondylitis: a systematic review. Pain. 2002;96(12):23-40.

51. Dojode CM. A randomised control trial to evaluate the efficacy of autologous blood injection versus local corticosteroid injection for treatment of lateral epicondylitis. Bone Joint Res. 2012;1(8):192-197.

52. Wolf JM, Ozer K, Scott F, et al. Comparison of autologous blood, corticosteroid, and saline injection in the treatment of lateral epicondylitis: a prospective, randomized, controlled multicenter study. J Hand Surg Am. 2011;36(8):1269-1272.

53. Gosens T, Peerbooms JC, van Laar W, et al. Ongoing positive effect of platelet-rich plasma versus corticosteroid injection in lateral epicondylitis: a double-blind randomized controlled trial with 2-year follow-up. Am J Sports Med. 2011;39(6):1200-1208.

54. Wong SM, Hui AC, Tong PY, et al. Treatment of lateral epicondylitis with botulinum toxin: a randomized, double-blind, placebo-controlled trial. Ann Intern Med. 2005;143(11):793-797.

55. Edwards SG, Calandruccio JH. Autologous blood injections for refractory lateral epicondylitis. J Hand Surg Am. 2003;28(2):272-278.

56. Thanasas C, Papadimitriou G, Charalambidis C, et al. Platelet-rich plasma versus autologous whole blood for the treatment of chronic lateral elbow epicondylitis: a randomized controlled clinical trial. $\mathrm{Am} \mathrm{J}$ Sports Med. 2011;39(10):2130-2134.

57. Krogh TP, Fredberg U, Stengaard-Pedersen K, et al. Treatment of lateral epicondylitis with platelet-rich plasma, glucocorticoid, or saline: a randomized, double-blind, placebo-controlled trial. Am J Sports Med. 2013;41(3):625-635.

58. Boswell SG, Schnabel LV, Mohammed HO, et al. Increasing platelet concentrations in leukocyte-reduced platelet-rich plasma decrease collagen gene synthesis in tendons. Am J Sports Med. 2014;42(1):42-49.

59. Peerbooms JC, Sluimer J, Bruijn DJ, et al. Positive effect of an autologous platelet concentrate in lateral epicondylitis in a double-blind randomized controlled trial: platelet-rich plasma versus corticosteroid injection with a 1-year follow-up. Am J Sports Med. 2010;38(2):255-262.

60. Stasinopoulos D, Johnson MI. Effectiveness of extracorporeal shock wave therapy for tennis elbow (lateral epicondylitis). Br J Sports Med. 2005;39(3):132-136

61. Speed CA, Nichols D, Richards C, et al. Extracorporeal shock wave therapy for lateral epicondylitis--a double blind randomised controlled trial. J Orthop Res. 2002;20(5):895-898.

62. Haake M, König IR, Decker T, et al. Extracorporeal Shock Wave Therapy Clinical Trial Group. Extracorporeal shock wave therapy in the treatment of lateral epicondylitis: a randomized multicenter trial. $J$ Bone Joint Surg Am. 2002;84-A(11):1982-1991.

63. Nirschl RP, Rodin DM, Ochiai DH, et al. Iontophoretic administration of dexamethasone sodium phosphate for acute epicondylitis. A randomized, double-blinded, placebo-controlled study. Am J Sports Med. 2003;31(2):189-195. 
64. Chesterton LS, Lewis AM, Sim J, et al. Transcutaneous electrical nerve stimulation as adjunct to primary care management for tennis elbow: pragmatic randomised controlled trial (TATE trial). Br J Sports Med. 2013;48(19):1458.

65. Kuklo TR, Taylor KF, Murphy KP, et al. Arthroscopic release for lateral epicondylitis: a cadaveric model. Arthroscopy. 1999;15(3):259-264.

66. Solheim E, Hegna J, Øyen J. Arthroscopic versus open tennis elbow release: 3- to 6-year results of a case-control series of 305 elbows. Arthroscopy. 2013;29(5):854-859.

67. Baker CL, Murphy KP, Gottlob CA, et al. Arthroscopic classification and treatment of lateral epicondylitis: two-year clinical results. J Shoulder Elbow Surg. 2000;9(6):475-482.

68. Owens BD, Murphy KP, Kuklo TR. Arthroscopic release for lateral epicondylitis. Arthroscopy. 2001;17(6):582-587.

69. Koh JS, Mohan PC, Howe TS, et al. Fasciotomy and surgical tenotomy for recalcitrant lateral elbow tendinopathy: early clinical experience with a novel device for minimally invasive percutaneous microresection. $\mathrm{Am}$ J Sports Med. 2013;41(3):636-644.

70. Baker CL, Baker CL. Long-term follow-up of arthroscopic treatment of lateral epicondylitis. Am J Sports Med. 2008;36(2):254-260.

71. Cho BK, Kim YM, Kim DS, et al. Mini-open muscle resection procedure under local anesthesia for lateral and medial epicondylitis. Clin Orthop Surg. 2009;1(3):123-127.

72. Lattermann C, Romeo AA, Anbari A, et al. Arthroscopic debridement of the extensor carpi radialis brevis for recalcitrant lateral epicondylitis. $J$ Shoulder Elbow Surg. 2010;19(5):651-656.

73. Baumgard SH, Schwartz DR. Percutaneous release of the epicondylar muscles for humeral epicondylitis. Am J Sports Med. 1982;10(4):233236.

74. Rhyou IH, Kim KW. Is posterior synovial plica excision necessary for refractory lateral epicondylitis of the elbow? Clin Orthop Relat Res. 2013;471(1):284-290.

75. Brooks-Hill AL, Regan WD. Extra-articular arthroscopic lateral elbow release. Arthroscopy. 2008;24(4):483-485.
76. Dunn JH, Kim JJ, Davis L, et al. Ten- to 14-year follow-up of the Nirschl surgical technique for lateral epicondylitis. Am J Sports Med. 2008;36(2):261-266.

77. Khan KM, Cook JL, Bonar F, et al. Histopathology of common tendinopathies. Update and implications for clinical management. Sports Med. 1999;27(6):393-408.

78. Ahmad Z, Siddiqui N, Malik SS, et al. Lateral epicondylitis: a review of pathology and management. Bone Joint J. 2013;95-B(9):1158-1164.

79. Struijs PA, Smidt N, Arola H, et al. Orthotic devices for the treatment of tennis elbow. Cochrane Database Syst Rev. 2002;(1):CD001821.

80. Coonrad RW, Hooper WR. Tennis elbow: its course natural history, conservative and surgical management. J Bone Joint Surg Am. 1973;55(6):1177-1182.

81. Oskarsson E, Gustafsson BE, Pettersson K, et al. Decreased intramuscular blood flow in patients with lateral epicondylitis. Scand J Med Sci Sports. 2007;17(3):211-215.

82. Chen FS1, Rokito AS, Jobe FW. Medial elbow problems in the overheadthrowing athlete. J Am Acad Orthop Surg. 2001;9(2):99-113.

83. Grana W. Medial epicondylitis and cubital tunnel syndrome in the throwing athlete. Clin Sports Med. 2001;20(3):541-548.

84. Gabel GT, Morrey BF. Operative treatment of medical epicondylitis. Influence of concomitant ulnar neuropathy at the elbow. J Bone Joint Surg Am. 1995;77(7):1065-1069.

85. Ollivierre CO, Nirschl RP, Pettrone FA. Resection and repair for medial tennis elbow. A prospective analysis. Am J Sports Med. 1995;23(2):214 221 .

86. Stahl S, Kaufman T. The efficacy of an injection of steroids for medial epicondylitis. A prospective study of sixty elbows. J Bone Joint Surg Am. 1997;79(11):1648-1652.

87. Vangsness CT, Jobe FW. Surgical treatment of medial epicondylitis. Results in 35 elbows. J Bone Joint Surg Br. 1991;73(3):409-411.

88. Jobe FW, Ciccotti MG. Lateral and medial epicondylitis of the elbow. $J$ Am Acad Orthop Surg. 1994;2(1):1-8. 